\title{
Representation of Spatial- and Object-Specific Behavioral Goals in the Dorsal Globus Pallidus of Monkeys during Reaching Movement
}

\author{
Yosuke Saga, ${ }^{1,2,3}$ Masashi Hashimoto, ${ }^{1,3}$ Léon Tremblay, ${ }^{2}$ Jun Tanji, ${ }^{3,4}$ and Eiji Hoshi ${ }^{1,3,5}$ \\ ${ }^{1}$ Frontal Lobe Function Project, Tokyo Metropolitan Institute of Medical Science, Tokyo 156-8506, Japan, ${ }^{2}$ Centre de Neuroscience Cognitive, Unité Mixte \\ de Recherche 5229, Centre National de la Recherche Scientifique, 69675, Bron, France, ${ }^{3}$ Tamagawa University Brain Science Institute, Tokyo 194-8610, \\ Japan, ${ }^{4}$ Tohoku University Brain Science Center, Sendai 980-8577, Japan, and ${ }^{5} J a p a n$ Science and Technology Agency, Core Research for Evolutional \\ Science and Technology, Tokyo 102-0076, Japan
}

The dorsal aspect of the globus pallidus (GP) communicates with the prefrontal cortex and higher-order motor areas, indicating that it plays a role in goal-directed behavior. We examined the involvement of dorsal GP neurons in behavioral goal monitoring and maintenance, essential components of executive function. We trained two macaque monkeys to choose a reach target based on relative target position in a spatial goal task or a target shape in an object-goal task. The monkeys were trained to continue to choose a certain behavioral goal when reward volume was constant and to switch the goals when the volume began to decrease. Because the judgment for the next goal was made in the absence of visual signals, the monkeys were required to monitor and maintain the chosen goals during the reaching movement. We obtained three major findings. (1) GP neurons reflected more of the relative spatial position than the shape of the reaching target during the spatial goal task. During the object-goal task, the shape of the reaching object was represented more than the relative position. (2) The selectivity of individual neurons for the relative position was enhanced during the spatial goal task, whereas the object-shape selectivity was enhanced during the object-goal task. (3) When the monkeys switched the goals, the selectivity for either the position or shape also switched. Together, these findings suggest that the dorsal GP is involved in behavioral goal monitoring and maintenance during execution of goal-oriented actions, presumably in collaboration with the prefrontal cortex.

\section{Introduction}

The basal ganglia (BG) contribute to multiple aspects of computational processes underlying the volitional behavior through the interconnections with the frontal cortex (Alexander et al., 1986; Graybiel, 2008). Above all, the involvement of the BG in the process of motor execution has been investigated intensively. Neurophysiological studies revealed that BG neurons of monkeys encode the direction of arm or eye movement during its execution (DeLong, 1971; Hikosaka and Wurtz, 1983b). Such representation is viewed as essential in the generation of movement as endorsed by the devastating motor deficits of the patients with parkinsonism (Marsden, 1982). In addition to motor parameters, the movement-period activity has been shown to encode the be-

Received March 18, 2013; revised Aug. 9, 2013; accepted Sept. 4, 2013.

Author contributions: Y.S., M.H., L.T., J.T., and E.H. designed research; Y.S., M.H., J.T., and E.H. performed research; Y.S., M.H., J.T., and E.H. contributed unpublished reagents/analytic tools; Y.S., J.T., and E.H. analyzed data; Y.S., L.T., J.T., and E.H. wrote the paper.

The authors declare no competing financial interests.

This work was supported by the Core Research for Evolutional Science and Technology (E.H.), Grant-in-Aid for Young Scientists 19670004 (E.H.), and a Research Fellowship for Young Scientists of Japan Society for the Promotion of Science (Y.S.). We thank Dr. Masaki Tanaka for the advice on recording neurons from the basal ganglia and T. Ogata and S. Hoffman for technical assistance.

Correspondence should be addressed to Dr. Eiji Hoshi, Frontal Lobe Function Project, Tokyo Metropolitan Institute of Medical Science, Kamikitazawa 2-1-6, Setagaya-ku, Tokyo 156-8506, Japan. E-mail: hoshi-ej@igakuken.or.jp.

DOI:10.1523/JNEUROSCI.1187-13.2013

Copyright $\odot 2013$ the authors $\quad 0270-6474 / 13 / 3316360-12 \$ 15.00 / 0$ havioral context, such as the presence or absence of sensory signals (Hikosaka and Wurtz, 1983a; Hikosaka et al., 1989; Mink and Thach, 1991; Kimura et al., 1992; Romo et al., 1992; Mushiake and Strick, 1995; Turner and Anderson, 2005), motor sequences (Kimura, 1990; Kermadi et al., 1993), and expected reward outcomes (Kawagoe et al., 1998). The context-dependent nature of the movement-period activity is considered to reflect the involvement of the BG in action generation based on sensory, memory, or reward information.

The context dependency of movement-period activity has also been revealed in neurons of the prefrontal cortex, with respect to the identity of an expected reward (Watanabe, 1996), the target shape to be acquired (Hoshi et al., 1998), or the relative target position (Niki, 1974). Subsequent studies found neural correlates of behavioral goals in the prefrontal cortex (Saito et al., 2005; Genovesio et al., 2012; Yamagata et al., 2012). Prefrontal goal representation during movement is thought to correspond to behavioralgoal monitoring and goal maintenance, essential components of executive functions underlying the goal-directed behavior (Luria, 1966; Wise et al., 1996; Miller and Cohen, 2001; Fuster, 2008; Tanji and Hoshi, 2008; Passingham and Wise, 2012), involving goal determination (Genovesio et al., 2006; Yamagata et al., 2012), action specification to achieve a goal (Sakagami and Tsutsui, 1999; Wallis and Miller, 2003; Cisek and Kalaska, 2005; Nakayama et al., 2008), and modification of behavior based on its outcome (Barraclough et al., 2004; Tsujimoto et al., 2012). 
What about the behavioral-goal representation in the BG during the motor execution period? We here investigated whether and how the behavioral goal is represented by movement-period activity in the dorsal globus pallidus (GP) that is interconnected across synapses with the prefrontal cortex (Middleton and Strick, 1994; Parent and Hazrati, 1995) and higher-order motor areas (Akkal et al., 2007; Saga et al., 2011). Because the GP is involved in providing intrinsic connections within the BG and output to external targets, rather than in receiving inputs from the cerebral cortex (Flaherty and Graybiel, 1993, 1994; Smith et al., 1998; Bolam et al., 2000), we considered that it is of crucial importance to explore the goal representation in the dorsal GP. Our results show neuronal activity specifying spatial- and object-specific behavioral goals during the motor-execution period, providing evidence that the cortico-BG "associative" circuit is involved in the behavioral goal monitoring and maintenance.

\section{Materials and Methods}

Animals and experimental conditions. We used two male monkeys (Macaca fuscata; 8.5 and $5.0 \mathrm{~kg}$ ) cared for in accordance with the National Institutes of Health guidelines and the guidelines of the Tokyo Metropolitan Institute of Medical Science and Tamagawa University. During the experimental sessions, each monkey sat in a chair with its head and left arm restrained. We installed a button at waist level in front of the chair that the monkeys could easily press and release with their right hand. A 19-inch color video monitor equipped with a touchsensitive screen was placed in front of the monkey $(30 \mathrm{~cm}$ from the eyes). Eye position was monitored at $120 \mathrm{~Hz}$ using an infrared eye-tracking system (resolution, $0.25^{\circ}$ visual angle; RHS-M; Applied Science Laboratories). The TEMPONET system (Reflective Computing) was used to control the behavioral task and the opening and closing of a solenoid valve serially installed in the reward delivery system, as well as to collect data at $1000 \mathrm{~Hz}$. A liquid reward (apple juice) was delivered via a stainless steel tube placed in front of the monkey's mouth.

Surgery and physiological recordings. Before initiation of the physiological recordings, aseptic surgery was performed under pentobarbital sodium anesthesia (20-25 mg/kg, i.v.) after induction of anesthesia using ketamine hydrochloride ( $10 \mathrm{mg} / \mathrm{kg}$, i.m.) and atropine sulfate. Antibiotics and analgesics were used to prevent postsurgical infection and pain. Polycarbonate and titanium screws were implanted in the skull, and two plastic pipes were rigidly attached with acrylic resin. Part of the skull over the left frontal lobe was removed, and a recording chamber was implanted to permit access to the BG.

Neuronal activity was recorded using a glass-insulated tungsten microelectrode $(\sim 2.0 \mathrm{M} \Omega$ at $1 \mathrm{kHz})$ inserted into the brain through a 23 -gauge guide tube that penetrated the dura mater. We used a hydraulic microdrive (MO-972; Narishige) to move the electrode using a micrometer step. Single-unit potentials were amplified using a multichannel processor and sorted using a multispike detector (MCP and ASD; Alpha Omega Engineering).

We recorded neuronal activity from the GP in the left hemisphere opposite to the task-performing right arm. During each recording session, we advanced the electrode vertically in the dorsoventral direction (see Fig. 2A). The electrode path went through the internal capsule or the striatum in which cellular activity was absent or the discharge rate was very low before coming in contact with neurons in the GP, which were identified by their high spontaneous discharge rate (DeLong, 1971; Arkadir et al., 2004).

Electromyographic activity was recorded using pairs of Teflon-coated stainless steel wires (single stranded, $0.0762 \mathrm{~mm}$ in diameter) inserted percutaneously.

Histology. After completion of the physiological recordings, one monkey was deeply anesthetized with an overdose of sodium pentobarbital $(50 \mathrm{mg} / \mathrm{kg}$ ) and killed by perfusion fixation with a mixture of $10 \%$ Formalin in $0.1 \mathrm{~m}$ phosphate buffer, $\mathrm{pH} 7.4$ (Saga et al., 2011). The brain was removed from the skull, postfixed in the same fresh fixative overnight at $4^{\circ} \mathrm{C}$, and placed in $0.1 \mathrm{M}$ phosphate buffer, $\mathrm{pH} 7.4$, containing $30 \%$ su- crose. Then serial coronal sections were cut at $60 \mu \mathrm{m}$ thickness on a freezing microtome. The sections were mounted on gelatin-coated glass slides, stained with $1 \%$ cresyl violet, and then examined under a light microscope (Eclipse 80i; Nikon).

Behavioral tasks. Monkeys were trained to perform two goal-oriented tasks, and each task was presented in a block of trials. In both tasks, after an intertrial interval of 2000-2500 ms, each trial began with the presentation of a fixation point (white square, visual angle of $1.4^{\circ}$ ) at the center of the screen. When the monkey pressed the hold button with its right hand and gazed at the fixation point for $600-1200 \mathrm{~ms}$, a choice cue was presented. In the spatial-goal (SG) task (Fig. 1A), the choice cue was a pair of blue circles or triangles (visual angle of $7^{\circ} \times 7^{\circ}$ for each; $11^{\circ}$ apart between the centers) that was randomly presented at one of four positions on the screen (Fig. 1C). When the color changed from blue to white (the GO signal) after a delay of $1500-2500 \mathrm{~ms}$, the monkey reached toward the right or left of the target pair. If the monkey touched either the right or left target associated with a reward, the choice cue immediately disappeared, and a drop of apple juice was delivered $1500 \mathrm{~ms}$ (Monkey 1) or $1200 \mathrm{~ms}$ (Monkey 2) later. If the monkey touched the target not associated with a reward, the choice cue immediately disappeared, and no reward was delivered before the next trial began. In the object-goal (OG) task (Fig. 1B), the choice cue consisted of a combination of two objects placed side by side, which was randomly presented at one of four positions on the screen (Fig. 1C). The right-left spatial order of the circle and triangle was also randomized. When the color changed from blue to white (the GO signal), the monkey reached toward the circle or triangle. If the shape associated with a reward was selected by touch, the choice cue immediately disappeared, and a drop of apple juice was delivered 1500 ms (Monkey 1) or $1200 \mathrm{~ms}$ (Monkey 2) later. If the monkey touched the object shape not associated with a reward, the choice cue immediately disappeared, and the next trial began without delivery of a reward.

No external signal acted as a cue that indicated the behavioral goal associated with a reward (i.e., the choice of either the right or left target in the SG task and the selection of either a circle or triangle in the OG task) in either the SG or OG task. Instead, monkeys determined the behavioral goal based on whether or not they received a reward in the preceding trial, (i.e., the outcome of their goal selection). The animals were required to select a particular behavioral goal associated with a reward in 10-15 successive trials, after which the reward-goal contingency was changed. Because the choice cue in the SG and OG tasks was presented at unpredictable locations on the screen and because in the OG task the right-left spatial order of the circle and triangle was also randomized, the animals determined the forthcoming action (i.e., actual target selection) only after the choice-cue appearance. During the block of 10-15 trials, an equal amount of reward was administered (constant-reward trials). During each block of trials, the animals were required to choose a particular behavioral goal associated with a reward. However, the reward amount varied according to an unpredictable reward-reduction schedule. After the constant-reward trials, the reward volume was reduced by $30 \%$ compared with that received in the preceding trial, such that, in five trials, the volume reached $17 \%$ of the original volume. If during these reducedreward trials the animals chose to select an alternative behavioral goal, the reward was restored to its full amount $(0.4 \mathrm{ml})$.

The SG and OG tasks were alternated every four trial blocks; a particular behavioral goal was rewarded in each block. In the four blocks of the SG or OG task, the animals were required to adopt each behavioral goal twice. During the transition from one task to the other, a visually guided task of 10-20 trials was intercalated. In this task, a circle or triangle target, which was always associated with the reward, was presented at one of the five potential positions on the screen (Fig. 1C). Otherwise, the temporal sequence of each trial was identical to that of the SG and OG tasks.

Data analyses. We applied statistical analyses to the neuronal activity of successful trials during the constraint-reward trials. We counted the number of neuronal spikes in successive $200 \mathrm{~ms}$ bins ( 21 bins in total) that occurred during four task events: (1) choice-cue appearance (six bins; three before and three after onset); (2) GO signal appearance (five bins; four before and one after onset); (3) target touch (four bins; two before and two after touch); and (4) reward delivery (six bins; three before and three after delivery). We classified a neuron as "task related" if 


\section{A Spatial goal (SG) task}

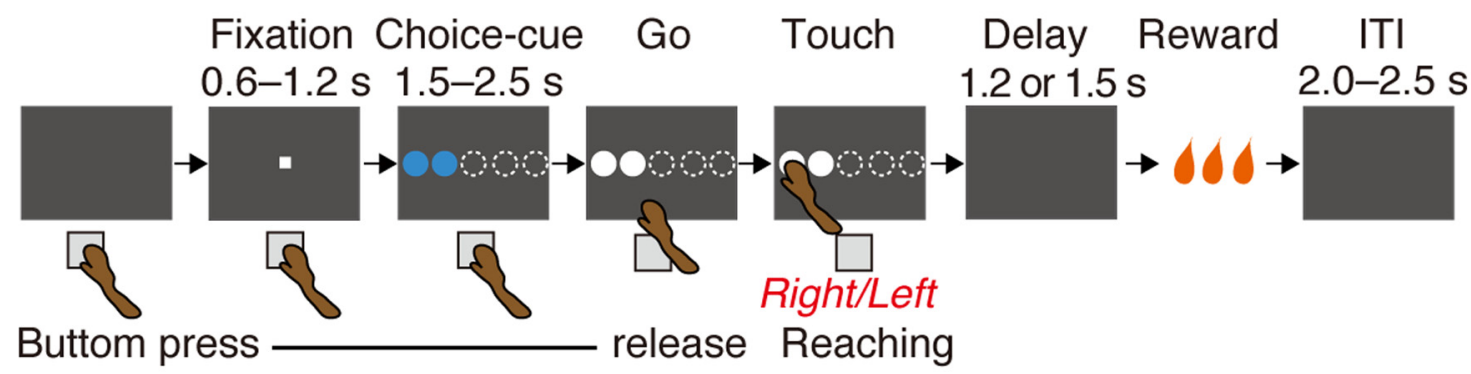

B Object goal (OG) task
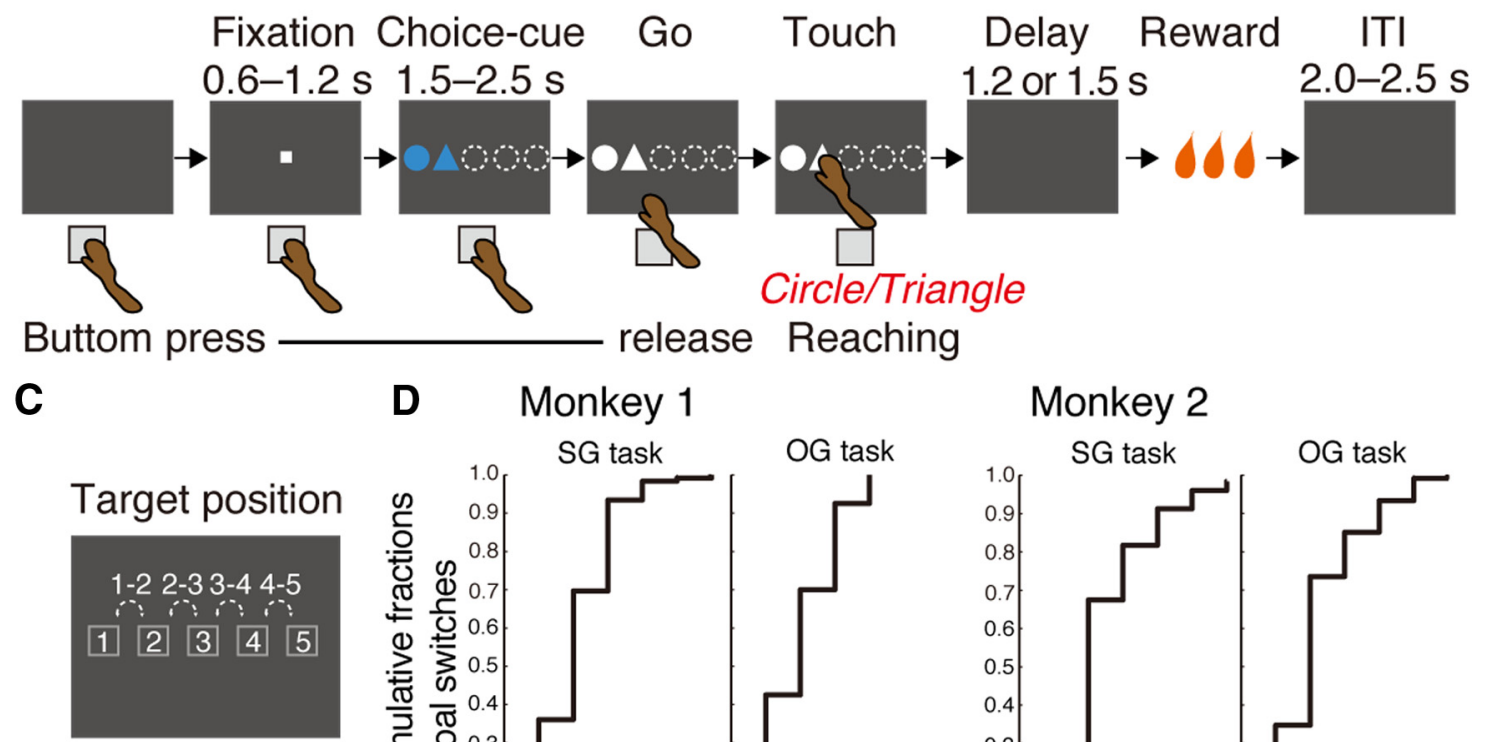

D Monkey 1

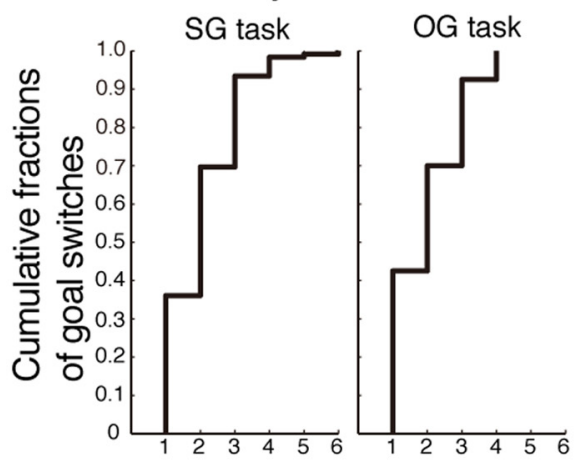

Monkey 2

Number of trials after reward began to decrease

Figure 1. Behavioral tasks, choice-cue locations, and behavioral results. $\boldsymbol{A}, \boldsymbol{B}$, Temporal sequence of behavioral events in the SG task $(\boldsymbol{A})$ and the $0 G$ task $(\boldsymbol{B})$. ITI, Intertrial interval. $\boldsymbol{C}$, Locations of the choice cue and target on the screen. The choice cue consisted of two potential targets appearing side by side (locations $1-5$, depicted by squares). D, Cumulative fractions summarizing the number of trials required for switching the goal after the volume of the reward began to decrease. Left panels, Results for Monkey 1 in the SG and $0 \mathrm{G}$ tasks; right panels, results for Monkey 2 in the SG and $O G$ tasks.

the distribution of the discharge rate (spikes per second) across the 21 bins was significantly different in at least 1 of 18 trial types (i.e., 18 combinations of goal and action; one-way ANOVA, $p<0.001$, not corrected).

The spike count data during each of the successive $200 \mathrm{~ms}$ bins were analyzed using ANOVA $(\alpha=0.01)$ with the main factors of relative position (RP; i.e., right vs left of the choice cue), target shape (TS; i.e., circle vs triangle), and actual (or absolute) target position (TP; i.e., the location of the correct target on the screen). Based on the analysis, we classified activity into eight categories: ( 1 ) only TP selective (TP, $<0.01 ; \mathrm{RP}, \geq 0.01 ; \mathrm{TS}, \geq 0.01$ ); (2) only RP selective (TP, $\geq 0.01$; RP, $<0.01$; TS, $\geq 0.01$ ); (3) only TS selective (TP, $\geq 0.01$; RP, $\geq 0.01$; TS, $<0.01$ ); (4) selective for both TP and RP (TP, $<0.01$; RP, $<0.01$; TS, $\geq 0.01$ ); (5) selective for both RP and TS (TP, $\geq 0.01$; $\mathrm{RP},<0.01$; TS, <0.01); (6) selective for both TP and TS (TP, $<0.01$; RP, $\geq 0.01$; TS, <0.01); (7) selective for all (TP, $<0.01$; RP, $<0.01$; TS, $<0.01$ ); and (8) selective for none (TP, $\geq 0.01$; RP, $\geq 0.01$; TS, $\geq 0.01$ ). We subsequently investigated whether the neurons classified as selective for TP reflected more of the choice-cue location than the reach TP or vice versa. We computed two indices: (1) the average activity difference of each TP neuron when the monkeys made leftward and rightward reaches within each choicecue location [the within-choice-cue difference (WCD)]; and (2) the average activity difference when the monkeys made leftward and rightward reaches to identical TPs on the screen [the within-identical-target difference (WTD)]. The smaller the value of an index was, the better neuron activity represented it. Thus, if the WCD was smaller than the WTD, the neuron was judged as reflecting more of the choice-cue location than the TP; it was classified as representing the choice-cue location. If the WTD was smaller than the WCD, the neuron was judged as reflecting more of the TP than the choice cue location; it was classified as representing the AP. Based on the results of these two sets of analyses, we classified activity of such single-factor selective neurons into four categories: (1) selective for the RP; (2) selective for the TS; (3) selective for the actual or absolute position of target in space (AP); and (4) selective for the choice-cue location.

\section{Results}

We trained two monkeys to perform two goal-directed tasks: (1) the SG task; and (2) the OG task. The choice cue for the SG and OG tasks was randomly presented at various locations on the screen; thus, the monkeys were able to specify the AP (i.e., the TP on the screen) only when the choice-cue appeared. Before the choice-cue appeared, the animals were only able to determine the 
Table 1. Reaction and movement times

\begin{tabular}{lll}
\hline & Task type & \\
\cline { 2 - 3 } & SG task (ms) & OG task (ms) \\
\hline Monkey 1 & & \\
$\quad$ Reaction time & $358 \pm 2$ & $346 \pm 2$ \\
$\quad$ Movement time & $325 \pm 3$ & $319 \pm 2$ \\
Monkey 2 & & $305 \pm 2$ \\
$\quad$ Reaction time & $315 \pm 2$ & $394 \pm 3$ \\
$\quad$ Movement time & $397 \pm 4$ & \\
\hline Values are means \pm SEs in milliseconds. & &
\end{tabular}

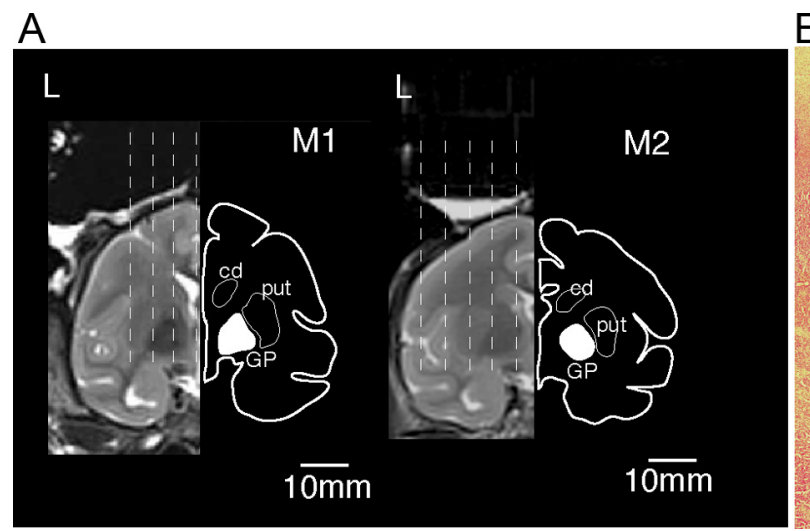

B

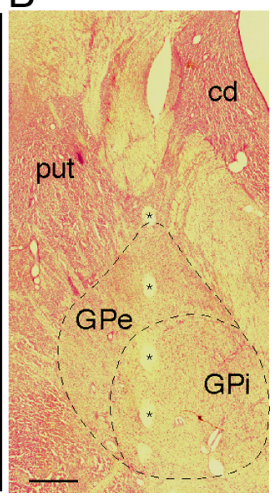

Figure 2. Recording sites. $\boldsymbol{A}$, MR images showing the GP of Monkey 1 (M1) and Monkey 2 (M2). The line drawings to the right of the MR images depict the cortical surface, the caudate nucleus (cd), and the putamen (put). The GP is white. $\boldsymbol{B}, A$ histological section from Monkey 2 in which the four markings $\left({ }^{*}\right)$ made by passing anodal direct currents through the tip of the recording electrode are shown. Scale bars: $\boldsymbol{A}, 10 \mathrm{~mm} ; \boldsymbol{B}, 1 \mathrm{~mm}$. L, Left hemisphere.

Table 2. Distribution of goal-selective GP neurons during each epoch of the SG task

\begin{tabular}{lllllll}
\hline \multicolumn{5}{c}{} & \multicolumn{6}{l}{ Task period } & & \\
\cline { 2 - 6 } Selectivity & Pre-choice & Post-choice & & \multicolumn{2}{l}{ Early } & Late \\
cue & Pre-G0 & movement & movement & Post-reward \\
\hline GPi $(n=244)$ & & & & & & \\
RP & $8(3)$ & $11(5)$ & $9(4)$ & $10(4)$ & $19(8)$ & $9(4)$ \\
TS & $0(0)$ & $5(2)$ & $3(1)$ & $3(1)$ & $4(2)$ & $4(2)$ \\
AP & $3(1)$ & $14(6)$ & $6(2)$ & $20(8)$ & $30(12)$ & $2(1)$ \\
GPe $(n=284)$ & & & & & & \\
RP & $12(4)$ & $8(3)$ & $13(5)$ & $18(6)$ & $17(6)$ & $7(2)$ \\
TS & $3(1)$ & $5(2)$ & $5(2)$ & $9(3)$ & $5(2)$ & $2(1)$ \\
AP & $1(0)$ & $25(9)$ & $3(1)$ & $31(11)$ & $36(13)$ & $4(1)$ \\
\hline
\end{tabular}

Pre-choice cue, $200 \mathrm{~ms}$ period preceding the choice-cue onset; Post-choice cue, 200 - $400 \mathrm{~ms}$ after the choice-cue onset; Pre-GO, 200 ms period preceding the G0-signal onset; Early movement, $200 \mathrm{~ms}$ period after the button release; Late movement, $200 \mathrm{~ms}$ period preceding the target touch; Post-reward, $200-400 \mathrm{~ms}$ after the reward delivery. The parentheses enclose the percentage of neurons relative to the total task-related neurons.

Table 3. Distribution of goal-selective GP neurons during each epoch of the $O G$ task

\begin{tabular}{|c|c|c|c|c|c|c|}
\hline \multirow[b]{2}{*}{ Selectivity } & \multicolumn{6}{|l|}{ Task period } \\
\hline & $\begin{array}{l}\text { Pre-choice } \\
\text { cue }\end{array}$ & $\begin{array}{l}\text { Post-choice } \\
\text { cue }\end{array}$ & Pre-GO & $\begin{array}{l}\text { Early } \\
\text { movement }\end{array}$ & $\begin{array}{l}\text { Late } \\
\text { movement }\end{array}$ & Post-reward \\
\hline \multicolumn{7}{|c|}{$\operatorname{GPi}(n=244)$} \\
\hline $\mathrm{RP}$ & $5(2)$ & $2(1)$ & $1(0)$ & $3(1)$ & $3(1)$ & $3(1)$ \\
\hline TS & $5(2)$ & $6(2)$ & $14(6)$ & $14(6)$ & $17(7)$ & $15(6)$ \\
\hline AP & $1(0)$ & $22(9)$ & $9(4)$ & $25(10)$ & $29(12)$ & $3(1)$ \\
\hline \multicolumn{7}{|c|}{$\mathrm{GPe}(n=284)$} \\
\hline $\mathrm{RP}$ & $1(0)$ & $5(2)$ & $3(1)$ & $4(1)$ & $11(4)$ & $1(0)$ \\
\hline TS & $4(1)$ & $6(2)$ & $12(4)$ & $16(6)$ & $20(7)$ & $13(5)$ \\
\hline AP & $0(0)$ & $22(8)$ & $9(3)$ & $26(9)$ & 30 (11) & $0(0)$ \\
\hline
\end{tabular}

Pre-choice cue, $200 \mathrm{~ms}$ period preceding the choice-cue onset; Post-choice-cue, 200 - $400 \mathrm{~ms}$ after the choice-cue onset; Pre-GO, $200 \mathrm{~ms}$ period preceding the $\mathrm{GO}$-signal onset; Early movement, $200 \mathrm{~ms}$ period after the button release; Late movement, $200 \mathrm{~ms}$ period preceding the target touch; Post-reward, $200-400 \mathrm{~ms}$ after the reward delivery. The parentheses enclose the percentage of neurons relative to the total task-related neurons.
$\mathrm{RP}$ (selection of right or left) in the SG task or the TS (selection of circle or triangle) in the OG task. Thus, the tasks included behavioral decisions at two hierarchical levels: (1) a higher level representing an abstract aspect of behavior (i.e., behavioral goal, the selection of right-left or object shape); and (2) a lower level representing a concrete or motor aspect (i.e., action). It is noteworthy that the reward was associated with the behavioral goal rather than the action. Moreover, because the choice cue immediately disappeared when the animals touched the target, no visible signals were available during the subsequent $1.2-1.5 \mathrm{~s}$ before reward delivery. Thus, to successfully perform the task, the monkeys were required to keep track of the behavioral goal during execution of the action and remember the goal until the reward was delivered. Thereafter, when the reward was delivered, they chose the goal for the next trial on the basis of the maintained information about the goal and the amount of reward, and subsequently the chosen goal, in turn, was kept as the information necessary for the next trial.

During the last four constant-reward trials, the success rate was $93 \%$ for Monkey 1 and $90 \%$ for Monkey 2 . When the reward volume began to decrease (reduced-reward trials), the monkeys switched the goal within a few trials (median of 2; Fig. 1D). These findings indicate that both animals maintained the behavioral goal associated with the reward during the constant-reward trials but quickly switched the goal during the reduced-reward trials. In both the SG and OG tasks, the reaction time (time from GO signal onset to button release) and movement time (time from button release to target touch) were $<400 \mathrm{~ms}$ (Table 1), indicating that the animals executed the reaching movements promptly after GO signal onset.

We recorded neuronal activity in the GP as the monkeys performed the tasks. The electrodes were advanced in the dorsoventral direction to sample neuronal activity in the associative territory located in the dorsalmost region of the GP (Parent and Hazrati, 1995; François et al., 2004). The recording sites were verified by examining magnetic resonance (MR) images $(3.0 \mathrm{~T}$, Sonata; Siemens) taken after the recording chamber was implanted (Fig. 2A) and histological sections with markings made by passing anodal direct currents $(20-40 \mu \mathrm{A}$ for $20 \mathrm{~s})$ through the tip of the recording electrode (Fig. 2B; Nomoto et al., 2010). In total, we recorded activity from 528 task-related GP neurons ( $n=409$ in Monkey $1, n=119$ in Monkey 2) primarily from the dorsal GP. Activity of these neurons was sampled in at least four blocks each of the SG and OG tasks. Based on the reconstruction of the recording sites, it was found that 244 task-related neurons were in the internal GP (GPi), and 284 task-related neurons were in the external GP (GPe).

\section{Temporal profiles of the number of goal-selective GPi and GPe neurons}

We investigated the time course of the appearance of neuronal activity selective for each of the RP, TS, and AP (Tables 2, 3). We first examined the temporal distribution of activity reflecting the $\mathrm{AP}$ (the actual target position on the screen). In the pre-choicecue period (200 ms period preceding the choice-cue onset) of either the SG or OG task, the AP was not represented before the 
appearance of the choice cue (binomial test, $p>0.12$ ). This was reasonable because it was impossible for monkeys to specify the forthcoming action at this stage; the choice cue was presented at various locations on the screen thereafter. In contrast, in the post-choice-cue period (200-400 ms after the choice cue onset), a subset of GPi and GPe neurons represented the AP (binomial test, $p<0.004$ ). This indicated that, once the choice cue was presented, the neural representation of reach action quickly developed, although the actual movement was executed $>1 \mathrm{~s}$ later. During the movement execution, $8-13 \%$ neurons represented the AP, and the fraction of the AP neurons reached a peak in the late movement period (200 ms period preceding the target touch). Thereafter, when the reward was delivered, the GP neurons ceased to represent the AP.

We subsequently analyzed the representation of abstract aspects of behavior: the RP and the TS. During the SG task, a subset of GPi and GPe neurons continuously represented the RP from the pre-choice-cue period to the late movement period (Table 2; binomial test, $p<0.01$ ). During the OG task, GPi and GPe neurons represented the TS from the pre-GO period to the postreward period (Table 3; binomial test, $p<0.01$ ). These analyses further revealed that the number of GP neurons selective for the RP during the SG task or for the TS during the OG task reached the peak in the late movement period.

Altogether, these observations revealed that it was just before the target touch (i.e., the late movement period) when the GP neurons best represented the RP during the SG task, the TS during the OG task, and the AP in both tasks. Accordingly, in the present study, we focused on the neuronal activity during this period. Furthermore, because the response properties of neurons in the GPi and GPe were found not different, we show the results of the GPi and GPe neurons together.

\section{Representation of the RP or TS of the behavioral target during movement}

Figure $3 A$ shows an example of neuronal activity that was suppressed during movement execution when the target to be reached was on the left of the choice cue. Another subset of neurons reflected the shape (circle or triangle) of objects to be reached in the OG task. Figure $3 B$ shows neuronal activity that was suppressed during execution of the movement when the TS was a circle.

While performing the SG task, 36 (7\%) of the 528 task-related neurons were selective for the RP alone during the $200 \mathrm{~ms}$ period preceding target touch (Table 4). During the OG task, 37 (7\%) neurons were selective for the TS alone (Table 4). Because only a few neurons were selective for more than one factor (Table 4), we focused on neurons selective for the RP or TS alone. Among the neurons selective for the RP or TS, only three represented the RP in the SG task and the TS in the OG task, indicating that primarily distinct groups of neurons represented the RP and TS.

We calculated the population activity of the behavioral-goalselective neurons by sorting activity according to trials that required reaching for right-left or triangle-circle targets. We plotted the time course of population activity that exhibited RP
Table 4. Number of GP neurons selective for the RP, TS, and AP of 528 task-related neurons

\begin{tabular}{llllllll}
\hline & \multicolumn{6}{l}{ Selectivity } \\
\cline { 2 - 8 } Task type & RP & \multicolumn{1}{c}{ TS } & AP & RP + AP & TS + AP & RP + TS & RP + TS + AP \\
\hline SG task & $36(7)$ & $9(2)$ & $66(13)$ & $10(2)$ & $4(1)$ & $1(0)$ & $1(0)$ \\
OG task & $14(3)$ & $37(7)$ & $59(11)$ & $3(1)$ & $7(1)$ & $0(0)$ & $0(0)$ \\
\hline
\end{tabular}

The parentheses enclose the percentage of neurons relative to the total task-related neurons.

selectivity during the SG task (Fig. $4 A$ ) and TS selectivity during the OG task (Fig. 4C) after separating the population of neurons that exhibited more (top trace) or less (bottom trace) activity during the $200 \mathrm{~ms}$ movement period while aiming for either of the two targets. We found that the target selectivity was expressed as a short-term decrease in activity before reaching toward one target and as a longer-lasting increase in activity (with long-lead premovement buildup) before reaching toward the other target (Fig. 4A, C, left). Subsequently, we examined the time courses of the changes in magnitude of RP and TS selectivity by plotting time-dependent differences in activity (Fig. 4A, $C$, right column). The selectivity gradually increased during the preparatory period and formed a peak during motor execution, culminating just before the target touch by the monkeys ( 25 spikes/s for RPselective neurons during the SG task and 24 spikes/s for TSselective neurons during the OG task). The selectivity diminished rapidly thereafter.

\section{Representation of RP and TS is behavioral-task dependent}

In the next analysis, we examined RP and TS selectivity in trials during which the selection of the RP or TS was not the behavioral task requirement. We found that only nine neurons (2\%) were selective for the TS (Table 4) during the SG task. Conversely, 14 (3\%) neurons were selective for the RP during the OG task. These results indicate that selectivity for the RP or TS appeared in a significantly smaller number of neurons unless the spatial- or object-specific selection was task relevant $\left(p<0.01, \chi^{2}\right.$ test; Table 4).

Given the task-dependent preponderance of spatial- or object-selective neurons, we compared the magnitudes of target selectivity by comparing the population activity of the RPselective neurons (identified in the SG task) during the OG task 
A

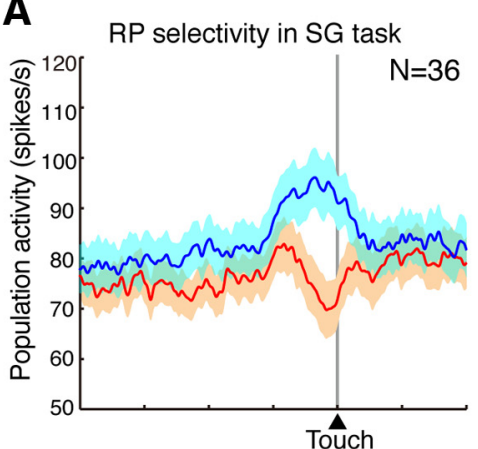

B

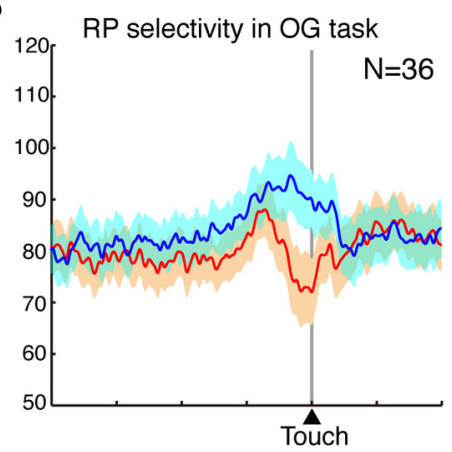

C

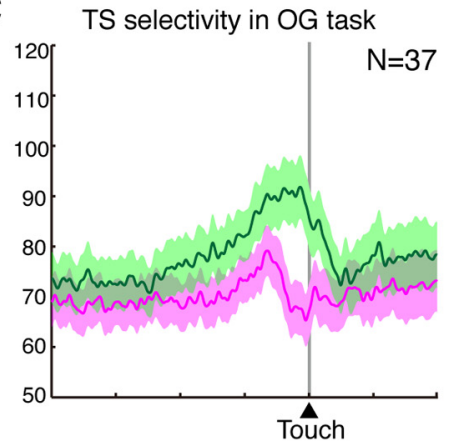

D

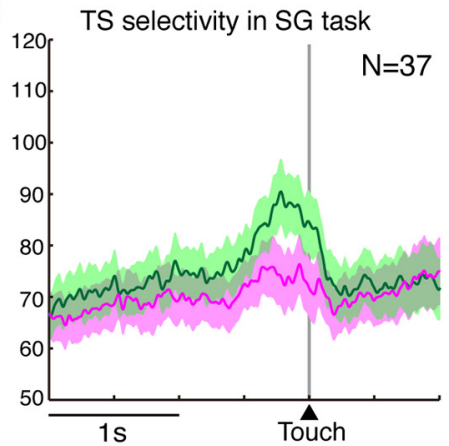

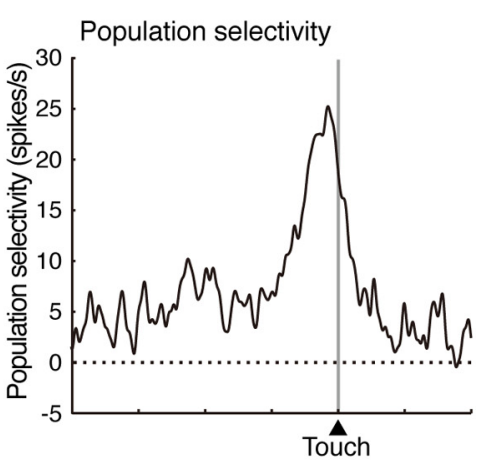
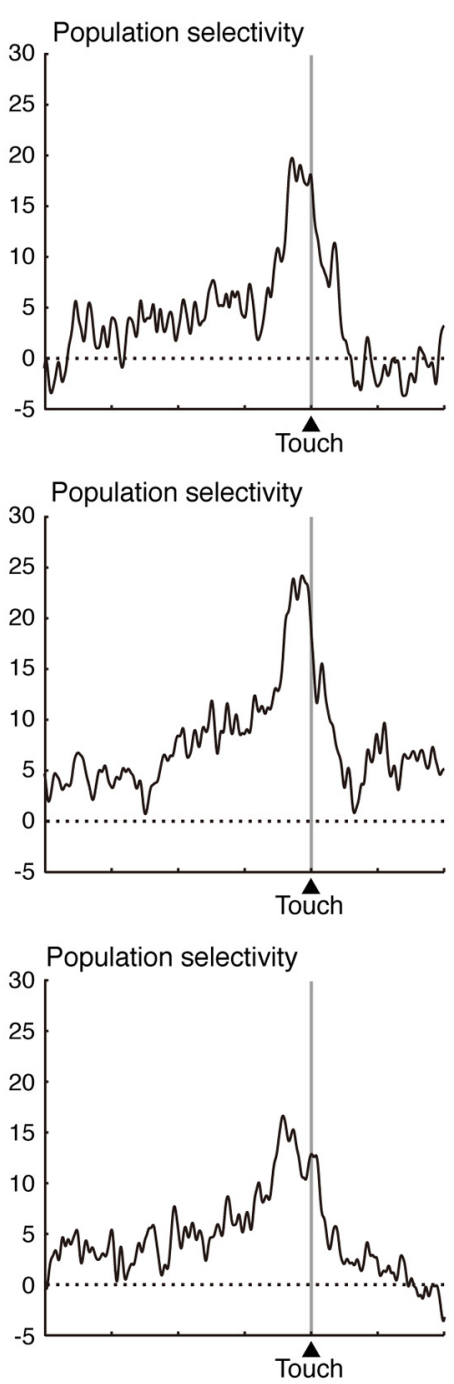

Figure 4. Population activity and selectivity of goal-selective neurons. A, Left panel shows population activity (mean \pm SEM) of the RP neurons in the SG task $(n=36)$. Only activity during the SG tasks was chosen. The activity was plotted separately for the trials in which the goals were the preferred (blue) and nonpreferred RPs (red). Right panel shows mean differences in population activities. The data were aligned with respect to the screen touch. $\boldsymbol{B}$, Population activity (left) and population selectivity (right) of the RP neurons identified in the SG task $(n=36)$ during the $O G$ task are shown in the same format as $\boldsymbol{A}$. C, Left panel shows population activity (mean \pm SEM) of the TS neurons during the $0 \mathrm{G}$ task $(n=37)$. Only activity during the $O G$ tasks was chosen. The activity was plotted separately for the trials in which the goals were the preferred (green) and nonpreferred (magenta) TSs. Right panel shows the mean differences in population activity. $\boldsymbol{D}$, Population activity (left) and population selectivity (right) of the TS neurons identified in the $0 \mathrm{G}$ task $(n=37)$ during the SG task are shown in the same format as $C$.

(Fig. $4 B$ ) versus during the SG task (Fig. $4 A)$ and the activity of the TS-selective neurons (identified in the OG task) during the SG task (Fig. 4D) versus during the OG task (Fig. 4C). RP-selective neurons exhibited less selectivity during the OG task (Fig. $4 B$ ) than during the $\mathrm{SG}$ task (Fig. $4 A$ ), and the TS-selective neurons exhibited less selectivity during the SG task (Fig. $4 D$ ) than during the OG task (Fig. 4C).

These findings were statistically verified using the following analyses. For the $\mathrm{RP}$-selective neurons during the SG task, we subtracted discharge rates for the "right" trials from those for the "left" trials. The calculation was performed separately with respect to the $S G$ and OG tasks (Fig. 5A). This analysis revealed that the absolute RP selectivity was greater during the SG task than during the OG task (Fig. $5 B ; p<0.0003$, Kolmogorov-Smirnov test). For the TS-selective neurons during the OG task, we subtracted discharge rates for the "triangle" trials from those for the "circle" trials (Fig. 5C). The TS absolute selectivity was significantly greater during the OG task than during the SG task (Fig. $5 D ; p<0.0001$, Kolmogorov-Smirnov test).

\section{Changes in target-selective neuronal activity while switching behavioral goals}

While performing both the spatialselection and object-selection tasks, the monkeys were required to switch their behavioral goals during the reduced-reward trials. We reasoned that, if the neuronal activity reflected the choice behavior of the monkeys, the RP and TS selectivity would covary with the behavioral goals chosen by the monkeys. To test this possibility, we examined how RP and TS selectivity would change in trials in which the monkeys switched goals. For both tasks, the target associated with higher (lower) discharge rate was referred to as the "preferred" ("nonpreferred") target. Neuronal activity remained high as long as the monkeys chose the preferred target in the SG task (Fig. 6A, blue trace) and OG task (Fig. 6B, red trace). Subsequently, neuronal activity for the preferred RP and TS began to decrease one trial before the monkey switched goals, and activity approximately reached the level of the nonpreferred RP and TS in the first trial after the monkeys switched goals. In contrast, neuronal activity for the nonpreferred RP and TS remained low as long as the monkeys continued to choose the nonpreferred target (Fig. $6 A$, red trace, $B$, green trace). Neuronal activity began to increase 
one trial before switching the goals. The nonpreferred RP and TS representations reached the level of the preferred RP and TS in the first trials after the switch. Furthermore, in the trials when the switch was made, the neuronal target selectivity was abolished. These results reveal that RP and TS selectivity were dynamically altered and closely correlated with the choice behavior of the monkeys.

\section{Representation of AP on the screen}

In addition to neurons that represented the RP and TS, a group of dorsal GP neurons preferentially reflected the AP (the reaching movement direction or the TP on the screen). The neuron depicted in Figure $7 A$ showed greater movement-period activity when the AP was on the left side of the screen, and the activity level was similar regardless of the task. Of the 528 task-related neurons, the number of neurons that were selective for the AP alone (ANOVA, $p<$ $0.01)$ totaled $66(13 \%)$ in the SG task and 59 (11\%) in the OG task. Among the neurons selective for the AP in either task $(n=101)$, 24 (24\%) were selective for the AP in both tasks. Figure $7 B$ shows the population activity calculated for the two APs leading to the highest and lowest discharge rates (left, SG task; right, OG task), and Figure $7 C$ shows population selectivity calculated as the difference in activity between the two APs. These data reveal that AP selectivity was prominent during execution of the reaching movement and that selectivity appeared as an increase as well as a decrease in activity.

We subsequently examined the distributions of the preferred and nonpreferred positions of the AP neurons; the TP associated with higher (lower) discharge rate was referred to as the preferred (nonpreferred) TP. We found that, in both tasks, the preferred and nonpreferred TPs tended to be more numerous at leftmost or rightmost position than at the positions between them (Table 5). We then examined the relationships between the preferred and nonpreferred TPs for each neuron. In 48 (73\%) of the $66 \mathrm{AP}$ neurons during the SG task, the preferred TPs and the nonpreferred TPs were in the opposite sides of the screen center. In 44 $(67 \%)$ neurons, there were at least two potential TPs between the preferred and nonpreferred TPs (Table 6). During the OG task, in $40(68 \%)$ neurons of the 59 AP neurons, the preferred TPs and the nonpreferred TPs were in the opposite sides of the screen center. In 37 (63\%) neurons, there were at least two potential TPs between the preferred and nonpreferred TPs (Table 6). These results revealed that, in a majority of AP neurons, the preferred and nonpreferred TPs were far apart from each other across the screen center, indicating that the AP neurons had a linear trend of location preference.

\section{Muscle activity and eye movement}

In sessions between neuronal recordings, we monitored the following muscles bilaterally during task performance: biceps and triceps brachii, deltoid (anterior, lateral, and posterior heads), trapezius, flexor, and extensor carpi radialis, supraspinatus, ingreen, $0 \mathrm{G}$ task.
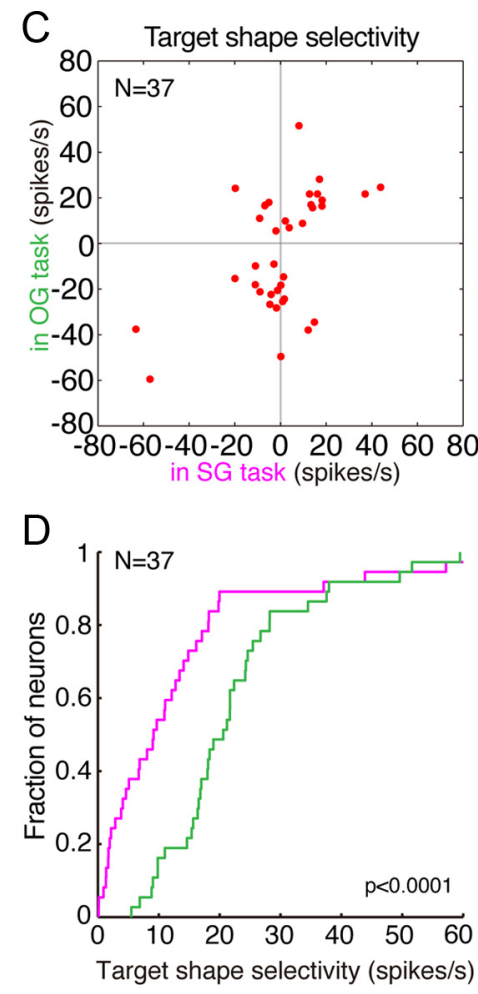

Figure 5. Task-dependent modification of RP and TS representations by single neurons. $\boldsymbol{A}$, Scatter plot comparing RP selectivity of RP neurons (identified in the SG task, $n=36$ ) in the SG task ( $x$-axis) and the OG task ( $y$-axis). RP selectivity from that to the circle goal. $\boldsymbol{D}$, Cumulative fractions of absolute TS selectivity for the data in $\boldsymbol{B}$ are shown. Magenta, SG task;

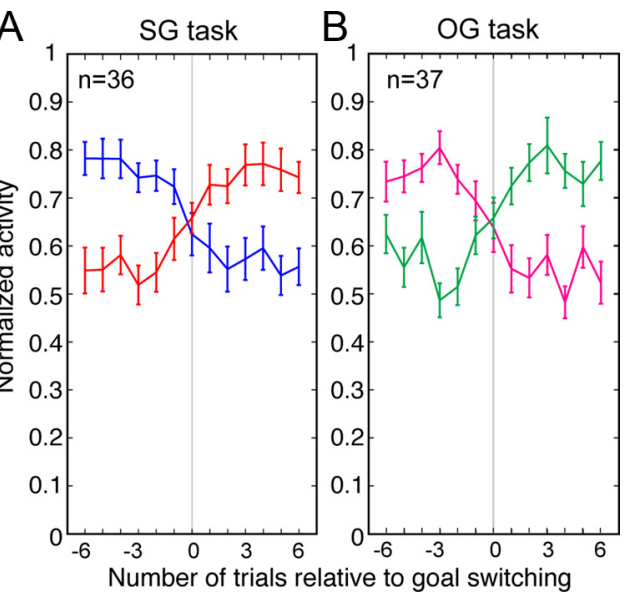

Figure 6. Modified activity of RP and TS neurons around goal switching. A, Modified activity in the $S G$ task. Mean population activity of neurons in the $S G$ task is plotted in \pm 6 trials relative to the trial when the monkeys switched goals. Before calculating population activity, the activity of each neuron was normalized with respect to the highest discharge rate of the 13 trials. The blue line indicates a trial sequence in which the monkeys switched from the preferred to nonpreferred RP. The red trace indicates a trial sequence in which the monkeys switched from the nonpreferred to the preferred RP. The error bars represent SEs. $B$, Modified activity in the OG task calculated in the same manner as described for the SG task $(\boldsymbol{A})$. The magenta line indicates a trial sequence in which the monkeys switched from the preferred to the nonpreferred TS. The green line indicates a trial sequence in which the monkeys switched from the nonpreferred to the preferred TS. 
A
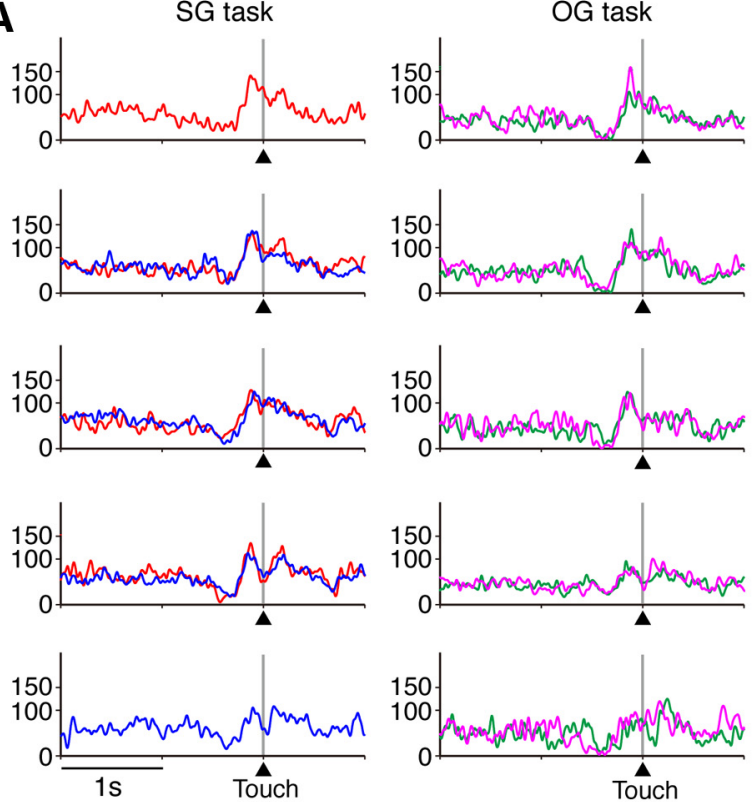

B

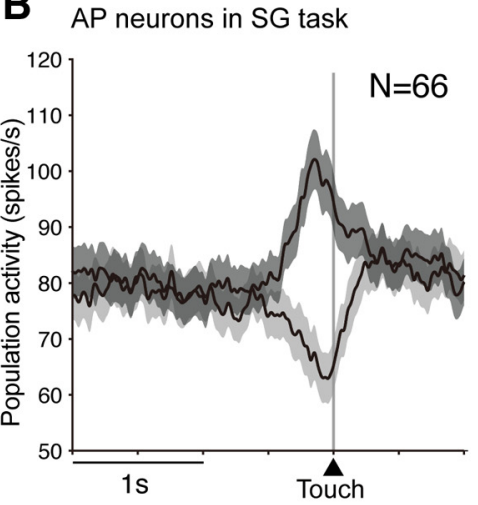

C Population selectivity in SG task

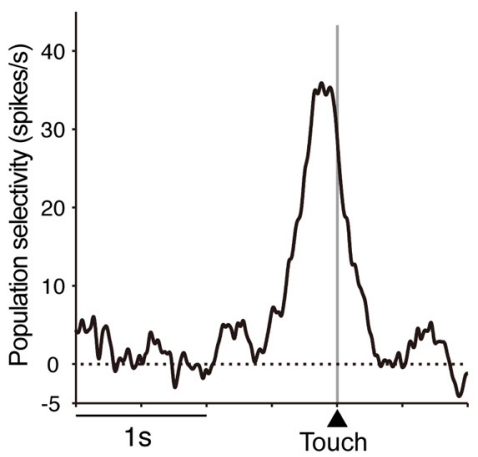

AP neurons in OG task

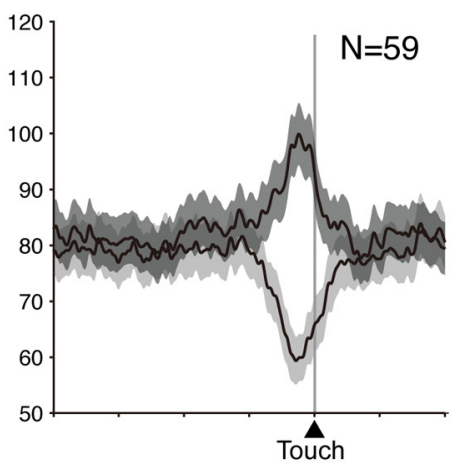

Population selectivity in OG task

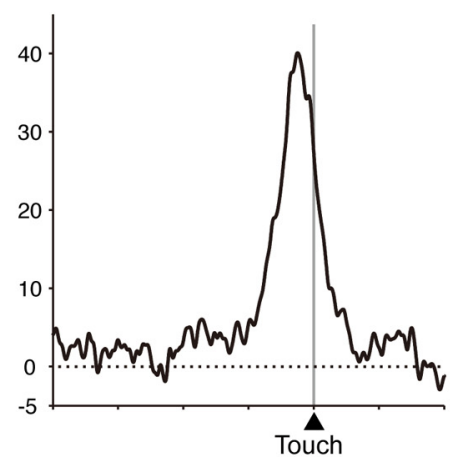

Figure 7. Neuronal activity reflecting the reach target AP. A, Spike-density function (smoothed using a Gaussian kernel; $\sigma=10 \mathrm{~ms}$ ) of GP neuronal activity. The ordinate represents the instantaneous firing rate (in spikes per second). The activity was aligned with the screen touch. Left column shows activity in theSG task (red, the left RP; blue, the right RP). The right column shows activity in the OG task (magenta, the circle TS; green, the triangle TS). From top to bottom, The TP was shifted from the leftmost to rightmost positions on the screen, as illustrated in the right insets. B, Population activity \pm SEM of neurons reflecting AP in the SG task (left, $n=66$ ) and OG task (right, $n=59$ ). Dark gray, Population activity when the monkeys touched a preferred target that caused the highest neuronal discharge rates. Light gray, Population activity when monkeys touched a nonpreferred target that caused the lowestneuronal discharge rates. C, Population selectivity calculated as the mean difference in activity between the preferred and nonpreferred trials.

fraspinatus, pectoralis major, rhomboid, and neck and paravertebral muscles. Muscles in the right forelimb, but not the neck/ paravertebral muscles or the muscles in the left forelimb, exhibited changes in activity during movement execution. We used the ANOVA to examine the selectivity for behavioral goal and action using muscle activity as the dependent variable. The muscles did not reflect the RP or TS (ANOVA, $p \geq 0.01$ ). During and around movement execution, the monkeys were not required to gaze at the fixation point. Thus, in advance of the execution of reaching movements, monkeys made saccadic eye movements to the reach targets. We investigated the time of occurrences of saccades before, during, and after the arm-reaching movements based on the continuous traces of the gaze directions monitored at $120 \mathrm{~Hz}$ using the infrared eye-tracking system. By detecting the timing of the last saccades to the reach targets relative to the reaching movements in randomly sampled 500 trials, we found that the monkeys made the last saccades $599 \pm 6 \mathrm{~ms}$ (mean \pm SEM, Monkey 1 ) and $407 \pm 4 \mathrm{~ms}$ (Monkey 2) before the target touch. These results revealed that, during the $200 \mathrm{~ms}$ period just before touching the targets, activity during which we analyzed, the monkeys made few eye movements if any, ruling out a possibility that eye movements could account for RP or TS selectivity. Altogether, these analyses revealed that the arm or eye movements could not account for the RP or TS selectivity.

\section{Location of neurons selective for RP, TS, and AP}

We reconstructed the recording sites based on the MR structural images of the two monkeys (Fig. 2A), the histological sections obtained in one monkey (Fig. $2 B$ ), and on documents summarizing the relationship between the depth of the electrodes and overall discharge properties of cells. Neurons specifically selective for RP, TS, or AP were found in the dorsal part of the GPe and GPi, with no segregation in their distributions (Fig. 8).

\section{Discussion}

We trained monkeys to achieve a behavioral goal in fulfilling either of two behavioral requirements imposed on two behavioral tasks. In both tasks, the selection of a forthcoming goal was made by monkeys themselves based on the amount of reward provided as the outcome of the behavioral-goal selection. Therefore, the monkeys were required to keep hold of the behavioral goal until the acceptance of a reward outcome. We found that movement-period activity in a subset of dorsal GP neurons exhibited either the selectivity for the RP during execution of the SG task or the selectivity for the TS during the OG task. We further found that the selectivity of these neurons underwent modulations closely reflecting the behavioral goal chosen by the 
Table 5. Distribution of preferred and nonpreferred target positions of AP neurons

\begin{tabular}{llrrrr}
\hline & \multicolumn{2}{l}{ Position } & & & \\
\cline { 2 - 6 } & T1 & T2 & T3 & T4 & T5 \\
\hline SG task $(n=66)$ & 17 & 12 & 6 & 13 & 18 \\
$\quad$ Preferred position & 27 & 7 & 9 & 8 & 15 \\
$\quad$ Nonpreferred position & & & & & \\
OG task $(n=59)$ & 25 & 4 & 6 & 11 & 13 \\
$\quad$ Preferred position & 17 & 5 & 12 & 11 & 14 \\
$\quad$ Nonpreferred position & & & & & \\
\hline
\end{tabular}

Table 6. Number of targets between preferred and nonpreferred positions for AP neurons

\begin{tabular}{lllll}
\hline & \multicolumn{4}{l}{ Number of targets } \\
\cline { 2 - 5 } Task type & 0 & 1 & 2 & 3 \\
\hline SG task $(n=66)$ & 5 & 17 & 27 & 17 \\
OG task $(n=59)$ & 4 & 18 & 21 & 16 \\
\hline
\end{tabular}

monkeys when they switched the goals. We also found that the activity representing the direction of movement in space was modified, depending on the SG or OG task. These findings are taken to indicate the involvement of the dorsal GP in representing the behavioral goals, as the information necessary to be monitored and held in memory, to be referred to at the time of motortarget decision.

\section{The design of behavioral tasks and the limitations of the present study}

The present behavioral task was designed to find the representation of spatial- and object-specific behavioral goals. Either goal information had to be monitored during a goal acquisition and to be maintained until the reward occurrence, to be referred to as the basis for the judgment to determine the behavioral goal in the next trial. Depending on the nature of reward (reward amount), a current behavioral goal was either preserved or discarded, corresponding to behavioral-goal "stay" or "shift" in a previous report (Genovesio et al., 2005). Conversely, the current behavioral task was not designed to study neural correlates of behavioralgoal switch or mechanisms underlying the behavioral strategies in task switching; the occurrences of behavioral-goal shift was by far infrequent than the occurrences of goal maintenance. Although our study addresses the issue of behavioral-goal maintenance, the exact nature of the involvement of the GP in behavioral-goal shift remain to be studied in future works.

\section{The dorsal GP belongs to the associative territory}

Anatomical studies revealed that the distinct subdivisions within each nucleus of the BG are preferentially interconnected with the distinct subdivisions within the frontal cortex (Alexander et al., 1986; Middleton and Strick, 2000) and that the entire frontal cortex as a whole communicates with the BG through multiple parallel circuits classified as associative, limbic, and motor circuits (Parent and Hazrati, 1995). In the GPi and GPe, the associative territory is in the dorsal portion, the limbic territory is in the ventral and rostral portion, and the sensorimotor territory is in the ventral and caudal portion. In accordance with this view, a pathophysiological study showed that microinjection of bicuculline, $\mathrm{a} \mathrm{GABA}_{\mathrm{A}}$ receptor antagonist, into each territory causes specific deficits in monkeys. Bicuculline injection into the associative territory of the GPe causes cognitive deficits similar to the hyperactivity disorder in humans, whereas the injection into the sensorimotor territory causes motor deficits and that into the limbic

\section{A Spatial-goal neurons in the SG task}

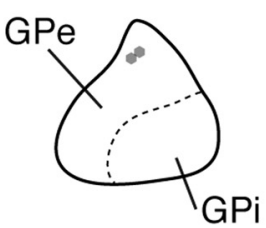
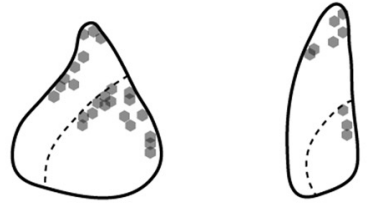

B Action neurons in the SG task
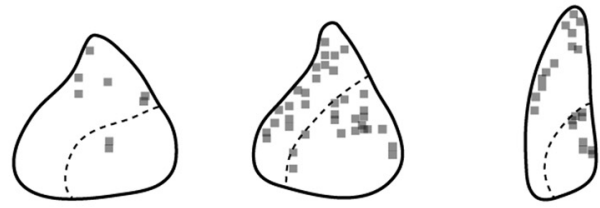

\section{Object-goal neurons in the OG task}
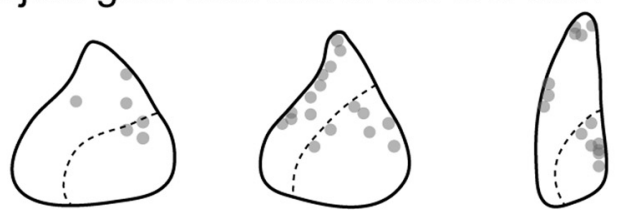

\section{Action neurons in the OG task}
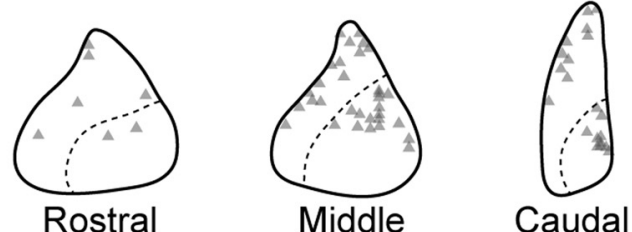

Lateral $\rfloor_{3 \mathrm{~mm}}^{\text {Dorsal }}$

Figure 8. Schematic of GP coronal sections showing the distribution of neurons selective for RP, TS, and AP. A-D, The solid lines represent the GP, and the dotted lines indicate the borders between the GPi and GPe segments. Sections from the rostral, middle, and caudal areas of the GP are shown from left to right. The distributions of neurons from the two monkeys are overlaid. Each point represents one neuron. $A$, Neurons selective for RP in the SG task $(n=36)$. B, Neurons selective for AP in the SG task $(n=66)$. C, Neurons selective for TS in the $0 \mathrm{G}$ task $(n=37)$. $\boldsymbol{D}$, Neurons selective for AP in the $\mathrm{OG}$ task $(n=59)$.

territory causes a stereotypy (Grabli et al., 2004). Together with the evidence that the dorsal GP preferentially projects to the lateral prefrontal cortex (Middleton and Strick, 1994, 2002) and higher-order motor areas (Akkal et al., 2007; Saga et al., 2011), these anatomical and pathophysiological observations show that the dorsal GP is a component of the associative territory and involved in cognitive processes beyond motor executions. Another major associative territory of the BG is the substantia nigra pars reticulata (SNpr). The SNpr, as well as the dorsal GPi, sends outputs to the prefrontal cortex via the thalamus (Middleton and Strick, 2002), indicating the SNpr is also involved in cognitive processes. Actually, neurons in the SNpr are shown to represent object values (Yasuda et al., 2012). These observations call for future investigations to examine functional specializations of the SNpr and dorsal GPi.

\section{The dorsal GP and representation of behavioral goal} and action

The role of the dorsal GP in behavioral control has been examined in functional studies. As for oculomotor control, neurons in 
the dorsal GPe are shown to have large visuospatial receptive and movement fields (Kato and Hikosaka, 1995; Shin and Sommer, 2010). Yoshida and Tanaka (2009) showed that modulations in dorsal GPe neuronal activity are enhanced during anti-saccades. These results suggest that the dorsal GP is of importance for behavioral factors other than movement execution. In line with this view, we here showed that movement-period activity in the dorsal GPi and GPe represents abstract behavioral goals and that the selectivity for action (i.e., target in space) is task dependent. Although we did not detect any differences in GPi and GPe neurons with respect to the goal and action representations during reaching movement (cf. Arimura et al., 2013), the GPi is at the output stage and GPe is at the intermediate stages of the information processing within the BG. In view of apparent differences in anatomical connectivity of the GPe and GPi, new lines of research are needed to reveal functional specializations in these areas.

BG representation of abstract aspects of motor behavior has been revealed in other reports. Putamen and GP neurons are shown to represent a TP or a movement direction as the intended movement direction (Mitchell et al., 1987; Alexander and Crutcher, 1990a,b). Here we extended these findings by showing that dorsal GP neurons represent the RP and TS of an intended target, namely the behavioral goal, beyond the movement direction in space.

Previous studies have also reported reward-dependent modulations of activity in the BG. Activity of neurons in the caudate nucleus is dynamically modified by reward expectation (Kawagoe et al., 1998) and shows anticipatory and memory-contingent activity when a reward is associated with a certain position or color (Lauwereyns et al., 2002). Movement-period activity in the GP is modified by reward expectation (Arkadir et al., 2004) and reward probability (Pasquereau et al., 2007). Premovement activity of striatal neurons reflects reward values associated with the direction of handle turns (Samejima et al., 2005). These modulations are considered to reflect the involvement of the BG in the action generation based on reward expectation. We here extended these concepts into the goal representations during reaching movement by showing that the OG selectivity is enhanced when the monkeys execute an action based on the object contingency with reward, as seen in the prefrontal cortex (Hoshi et al., 1998, 2000). We also showed in the present study that the SG selectivity during movement, which was also found in the prefrontal cortex (Yamagata et al., 2012), is enhanced when they execute an action based on the spatial contingency. These findings indicate that the dorsal GP and the prefrontal cortex dynamically represent the spatial- and object-specific goals during movement in a goal-oriented manner.

However, it is also conceivable that the exact functional roles played by the BG and the prefrontal cortex may differ. One intriguing possibility is that the prefrontal cortex takes part in monitoring and maintenance of behavioral goal in a new context, whereas the BG do so in a learned or familiar context (Toni et al., 2002). In line with this view, the present study revealed that a subset of GP neurons preferentially represents behavioral goals when the choice behavior is established and stable. Houk and Wise (1995) proposed that the BG play a role in contextual pattern recognition for triggering sustained activity enhancement or suppression in the thalamus and the cerebral cortex. According to this view, one aspect of goal representation during movement may be to register the context of goals to initiate or suppress subsequent information processing in the cerebral cortex for goal-directed behavior and also to inhibit opposing or irrelevant goals (Mink, 1996; Hazy et al., 2007; McNab and Klingberg, 2008).

In humans, Corbetta et al. (1991) reported that the dorsal GP and caudate nucleus are involved in selective attention to visual features. The goal representation revealed in the present study is considered to stem from selective attention to the task-relevant features of the reach target during movement execution. Monchi et al. (2001) revealed neurovascular activation in the caudate nucleus of human subjects while they performed the Wisconsin Card Sorting Test (WCST), a test of executive function (Milner, 1963). Furthermore, WCST performance deteriorated after impairment of circuits comprising the prefrontal cortex and BG (Cummings, 1993; Dubois and Pillon, 1997). Abstract goal representation observed in the dorsal GP may play a part in the successful performance of the WCST by providing neural substrates for behavioral goal monitoring and maintenance during the card sorting, particularly when attended features are kept constant.

In addition to the goal representation, we found that a subset of the dorsal GP neurons encodes the direction of action. The action representation was generally linear rather than categorical like the goal representation. Because the projections from the dorsal GP to the primary motor cortex are meager, these neurons may be involved in specifying the TP in space. Of the 101 neurons selective for the AP in either the SG or OG task, 77 (76\%) neurons showed this property only in either task. The task dependency of the activity reflecting action indicates that the action representation in the dorsal GP is under a strong influence of the behavioral goals.

Altogether, the findings in the present study suggest that the dorsal GP is involved in behavioral goal monitoring and maintenance during execution of goal-oriented actions, presumably in collaboration with the prefrontal cortex.

\section{References}

Akkal D, Dum RP, Strick PL (2007) Supplementary motor area and presupplementary motor area: targets of basal ganglia and cerebellar output. J Neurosci 27:10659-10673. CrossRef Medline

Alexander GE, Crutcher MD (1990a) Preparation for movement: neural representations of intended direction in three motor areas of the monkey. J Neurophysiol 64:133-150. Medline

Alexander GE, Crutcher MD (1990b) Neural representations of the target (goal) of visually guided arm movements in three motor areas of the monkey. J Neurophysiol 64:164-178. Medline

Alexander GE, DeLong MR, Strick PL (1986) Parallel organization of functionally segregated circuits linking basal ganglia and cortex. Annu Rev Neurosci 9:357-381. CrossRef Medline

Arimura N, Nakayama Y, Yamagata T, Tanji J, Hoshi E (2013) Involvement of the globus pallidus in behavioral goal determination and action specification. J Neurosci 33:13639-13653. CrossRef Medline

Arkadir D, Morris G, Vaadia E, Bergman H (2004) Independent coding of movement direction and reward prediction by single pallidal neurons. J Neurosci 24:10047-10056. CrossRef Medline

Barraclough DJ, Conroy ML, Lee D (2004) Prefrontal cortex and decision making in a mixed-strategy game. Nat Neurosci 7:404-410. CrossRef Medline

Bolam JP, Hanley JJ, Booth PA, Bevan MD (2000) Synaptic organisation of the basal ganglia. J Anat 196:527-542. CrossRef Medline

Cisek P, Kalaska JF (2005) Neural correlates of reaching decisions in dorsal premotor cortex: specification of multiple direction choices and final selection of action. Neuron 45:801-814. CrossRef Medline

Corbetta M, Miezin FM, Dobmeyer S, Shulman GL, Petersen SE (1991) Selective and divided attention during visual discriminations of shape, color, and speed: functional anatomy by positron emission tomography. J Neurosci 11:2383-2402. Medline

Cummings JL (1993) Frontal-subcortical circuits and human behavior. Arch Neurol 50:873-880. CrossRef Medline 
DeLong MR (1971) Activity of pallidal neurons during movement. J Neurophysiol 34:414-427. Medline

Dubois B, Pillon B (1997) Cognitive deficits in Parkinson's disease. J Neurol 244:2-8. Medline

Flaherty AW, Graybiel AM (1993) Output architecture of the primate putamen. J Neurosci 13:3222-3237. Medline

Flaherty AW, Graybiel AM (1994) Input-output organization of the sensorimotor striatum in the squirrel monkey. J Neurosci 14:599-610. Medline

François C, Grabli D, McCairn K, Jan C, Karachi C, Hirsch EC, Féger J, Tremblay L (2004) Behavioural disorders induced by external globus pallidus dysfunction in primates II. Anatomical study. Brain 127:20552070. CrossRef Medline

Fuster JM (2008) The prefrontal cortex, Ed 4. London: Academic.

Genovesio A, Brasted PJ, Mitz AR, Wise SP (2005) Prefrontal cortex activity related to abstract response strategies. Neuron 47:307-320. CrossRef Medline

Genovesio A, Brasted PJ, Wise SP (2006) Representation of future and previous spatial goals by separate neural populations in prefrontal cortex. J Neurosci 26:7305-7316. CrossRef Medline

Genovesio A, Tsujimoto S, Wise SP (2012) Encoding goals but not abstract magnitude in the primate prefrontal cortex. Neuron 74:656-662. CrossRef Medline

Grabli D, McCairn K, Hirsch EC, Agid Y, Féger J, François C, Tremblay L (2004) Behavioural disorders induced by external globus pallidus dysfunction in primates: I. Behavioural study. Brain 127:2039-2054. CrossRef Medline

Graybiel AM (2008) Habits, rituals, and the evaluative brain. Annu Rev Neurosci 31:359-387. CrossRef Medline

Hazy TE, Frank MJ, O’Reilly RC (2007) Towards an executive without a homunculus: computational models of the prefrontal cortex/basal ganglia system. Philos Trans R Soc Lond B Biol Sci 362:1601-1613. CrossRef Medline

Hikosaka O, Wurtz RH (1983a) Visual and oculomotor functions of monkey substantia nigra pars reticulata. I. Relation of visual and auditory responses to saccades. J Neurophysiol 49:1230-1253. Medline

Hikosaka O, Wurtz RH (1983b) Visual and oculomotor functions of monkey substantia nigra pars reticulata. III. Memory-contingent visual and saccade responses. J Neurophysiol 49:1268-1284. Medline

Hikosaka O, Sakamoto M, Usui S (1989) Functional properties of monkey caudate neurons. I. Activities related to saccadic eye movements. J Neurophysiol 61:780-798. Medline

Hoshi E, Shima K, Tanji J (1998) Task-dependent selectivity of movementrelated neuronal activity in the primate prefrontal cortex. J Neurophysiol 80:3392-3397. Medline

Hoshi E, Shima K, Tanji J (2000) Neuronal activity in the primate prefrontal cortex in the process of motor selection based on two behavioral rules. J Neurophysiol 83:2355-2373. Medline

Houk JC, Wise SP (1995) Distributed modular architectures linking basal ganglia, cerebellum, and cerebral cortex: their role in planning and controlling action. Cereb Cortex 5:95-110. CrossRef Medline

Kato M, Hikosaka O (1995) Function of the indirect pathway in the basal ganglia oculomotor system: visuo-oculomotor activities of external pallidum neurons. In: Age-related dopamine-dependent disorders (monographs in neural sciences) (Segawa M, Nomura Y, eds), pp 178-187. Basel: Karger.

Kawagoe R, Takikawa Y, Hikosaka O (1998) Expectation of reward modulates cognitive signals in the basal ganglia. Nat Neurosci 1:411-416. CrossRef Medline

Kermadi I, Jurquet Y, Arzi M, Joseph JP (1993) Neural activity in the caudate nucleus of monkeys during spatial sequencing. Exp Brain Res 94: 352-356. Medline

Kimura M (1990) Behaviorally contingent property of movement-related activity of the primate putamen. J Neurophysiol 63:1277-1296. Medline

Kimura M, Aosaki T, Hu Y, Ishida A, Watanabe K (1992) Activity of primate putamen neurons is selective to the mode of voluntary movement: visually guided, self-initiated or memory-guided. Exp Brain Res 89:473-477. Medline

Lauwereyns J, Takikawa Y, Kawagoe R, Kobayashi S, Koizumi M, Coe B, Sakagami M, Hikosaka O (2002) Feature-based anticipation of cues that predict reward in monkey caudate nucleus. Neuron 33:463-473. CrossRef Medline
Luria AR (1966) Higher cortical functions in man. New York: Basic Book.

Marsden CD (1982) The mysterious motor function of the basal ganglia: the Robert Wartenberg Lecture. Neurology 32:514-539. CrossRef Medline

McNab F, Klingberg T (2008) Prefrontal cortex and basal ganglia control access to working memory. Nat Neurosci 11:103-107. CrossRef Medline

Middleton FA, Strick PL (1994) Anatomical evidence for cerebellar and basal ganglia involvement in higher cognitive function. Science 266:458 461. CrossRef Medline

Middleton FA, Strick PL (2000) Basal ganglia and cerebellar loops: motor and cognitive circuits. Brain Res Brain Res Rev 31:236-250. Medline

Middleton FA, Strick PL (2002) Basal-ganglia 'projections' to the prefrontal cortex of the primate. Cereb Cortex 12:926-935. CrossRef Medline

Miller EK, Cohen JD (2001) An integrative theory of prefrontal cortex function. Annu Rev Neurosci 24:167-202. CrossRef Medline

Milner B (1963) Effects of different brain lesions on card sorting: the role of the frontal lobes. Arch Neurol 9:90. CrossRef

Mink JW (1996) The basal ganglia: focused selection and inhibition of competing motor programs. Prog Neurobiol 50:381-425. CrossRef Medline

Mink JW, Thach WT (1991) Basal ganglia motor control. I. Nonexclusive relation of pallidal discharge to five movement modes. J Neurophysiol 65:273-300. Medline

Mitchell SJ, Richardson RT, Baker FH, DeLong MR (1987) The primate globus pallidus: neuronal activity related to direction of movement. Exp Brain Res 68:491-505. Medline

Monchi O, Petrides M, Petre V, Worsley K, Dagher A (2001) Wisconsin Card Sorting revisited: distinct neural circuits participating in different stages of the task identified by event-related functional magnetic resonance imaging. J Neurosci 21:7733-7741. Medline

Mushiake H, Strick PL (1995) Pallidal neuron activity during sequential arm movements. J Neurophysiol 74:2754-2758. Medline

Nakayama Y, Yamagata T, Tanji J, Hoshi E (2008) Transformation of a virtual action plan into a motor plan in the premotor cortex. J Neurosci 28:10287-10297. CrossRef Medline

Niki H (1974) Prefrontal unit activity during delayed alternation in the monkey. II. Relation to absolute versus relative direction of response. Brain Res 68:197-204. CrossRef Medline

Nomoto K, Schultz W, Watanabe T, Sakagami M (2010) Temporally extended dopamine responses to perceptually demanding rewardpredictive stimuli. J Neurosci 30:10692-10702. CrossRef Medline

Parent A, Hazrati LN (1995) Functional anatomy of the basal ganglia. I. The cortico-basal ganglia-thalamo-cortical loop. Brain Res Brain Res Rev 20: 91-127. CrossRef Medline

Pasquereau B, Nadjar A, Arkadir D, Bezard E, Goillandeau M, Bioulac B, Gross CE, Boraud T (2007) Shaping of motor responses by incentive values through the basal ganglia. J Neurosci 27:1176-1183. CrossRef Medline

Passingham R, Wise SP (2012) The neurobiology of the prefrontal cortex: anatomy, evolution, and the origin of insight. Oxford: Oxford UP.

Romo R, Scarnati E, Schultz W (1992) Role of primate basal ganglia and frontal cortex in the internal generation of movements. II. Movementrelated activity in the anterior striatum. Exp Brain Res 91:385-395. CrossRef Medline

Saga Y, Hirata Y, Takahara D, Inoue K, Miyachi S, Nambu A, Tanji J, Takada M, Hoshi E (2011) Origins of multisynaptic projections from the basal ganglia to rostrocaudally distinct sectors of the dorsal premotor area in macaques. Eur J Neurosci 33:285-297. CrossRef Medline

Saito N, Mushiake H, Sakamoto K, Itoyama Y, Tanji J (2005) Representation of immediate and final behavioral goals in the monkey prefrontal cortex during an instructed delay period. Cereb Cortex 15:1535-1546. CrossRef Medline

Sakagami M, Tsutsui K (1999) The hierarchical organization of decision making in the primate prefrontal cortex. Neurosci Res 34:79-89. Medline

Samejima K, Ueda Y, Doya K, Kimura M (2005) Representation of actionspecific reward values in the striatum. Science 310:1337-1340. CrossRef Medline

Shin S, Sommer MA (2010) Activity of neurons in monkey globus pallidus during oculomotor behavior compared with that in substantia nigra pars reticulata. J Neurophysiol 103:1874-1887. CrossRef Medline

Smith Y, Bevan MD, Shink E, Bolam JP (1998) Microcircuitry of the direct and indirect pathways of the basal ganglia. Neuroscience 86:353-387. CrossRef Medline 
Tanji J, Hoshi E (2008) Role of the lateral prefrontal cortex in executive behavioral control. Physiol Rev 88:37-57. CrossRef Medline

Toni I, Rowe J, Stephan KE, Passingham RE (2002) Changes of corticostriatal effective connectivity during visuomotor learning. Cereb Cortex 12:1040-1047. CrossRef Medline

Tsujimoto S, Genovesio A, Wise SP (2012) Neuronal activity during a cued strategy task: comparison of dorsolateral, orbital, and polar prefrontal cortex. J Neurosci 32:11017-11031. CrossRef Medline

Turner RS, Anderson ME (2005) Context-dependent modulation of movement-related discharge in the primate globus pallidus. J Neurosci 25:2965-2976. CrossRef Medline

Wallis JD, Miller EK (2003) From rule to response: neuronal processes in the premotor and prefrontal cortex. J Neurophysiol 90:1790-1806. CrossRef Medline
Watanabe M (1996) Reward expectancy in primate prefrontal neurons. Nature 382:629-632. CrossRef Medline

Wise SP, Murray EA, Gerfen CR (1996) The frontal cortex-basal ganglia system in primates. Crit Rev Neurobiol 10:317-356. CrossRef Medline

Yamagata T, Nakayama Y, Tanji J, Hoshi E (2012) Distinct information representation and processing for goal-directed behavior in the dorsolateral and ventrolateral prefrontal cortex and the dorsal premotor cortex. J Neurosci 32:12934-12949. CrossRef Medline

Yasuda M, Yamamoto S, Hikosaka O (2012) Robust representation of stable object values in the oculomotor basal ganglia. J Neurosci 32:16917-16932. CrossRef Medline

Yoshida A, Tanaka M (2009) Enhanced modulation of neuronal activity during antisaccades in the primate globus pallidus. Cereb Cortex 19:206217. CrossRef Medline 